\title{
Targeting modifiable risk factors in age-related macular degeneration in optometric practice in Sweden
}

This article was published in the following Dove Press journal:

Clinical Optometry

19 April 2017

Number of times this article has been viewed

\author{
Lene Martin ${ }^{1,2}$ \\ 'School of Health, Care and Social \\ Welfare, Mälardalen University, \\ Eskilstuna, Sweden; ${ }^{2}$ School of Health \\ Sciences, City, University of London, \\ London, UK
}

Purpose: The purpose of this study was to investigate the extent to which ophthalmologists and optometrists in Sweden recommend the use of nutritional supplements, changes in diet, or smoking cessation to patients who are at risk of or with signs of age-related macular degeneration (AMD). In addition, this study also examined how these practitioners rate the strength of evidence for nutritional supplements in AMD management and which sources of information they consult to determine supplement recommendations for the prevention or treatment of AMD. Methods: This study implemented a cross-sectional design using data from a questionnaire. All Swedish optometrists and ophthalmologists who were registered in the membership databases of their respective professional organizations were invited to participate. The questionnaire contained 18 forced choice questions and one free text question and was organized into the following four sections: use of nutritional supplements, dietary advice, smoking and eye diseases, and strength of evidence and the sources of information regarding nutritional supplement interventions.

Results: The response rate was $40.3 \%$ for optometrists and $5 \%$ for ophthalmologists. Optometrists were more likely than ophthalmologists to recommend nutritional supplements in AMD and provided significantly more advice about diet than did the ophthalmologists for both patients at risk for AMD and those with established disease. The ophthalmologists were more likely than the optometrists to rely on the findings from the age-related eye disease studies of AMD regarding treatment with and selection of supplements and to recommend smoking cessation. Conclusion: Common evidence-based strategies for AMD management among eye care professionals would presumably be beneficial for AMD patients. Targeted education and implementation strategies may be needed.

Keywords: age-related macular degeneration, diet, smoking, nutritional supplements

\section{Introduction}

Age-related macular degeneration (AMD) affects individuals above the age of 50 and is a major cause of severe visual impairment in older populations in industrial countries. ${ }^{1,2}$ AMD is characterized by progressive destruction of the retinal pigment epithelial cells and photoreceptors ${ }^{3}$ due to low-grade inflammation, ischemia, and oxidative stress. ${ }^{4,5}$ The natural defenses against oxidative stress involve antioxidants, either derived from the diet or from natural substances. High local concentrations of pigments such as lutein, zeaxanthin, and meso-zeaxanthin result in a yellow color in the macular region that can be observed when the retina is illuminated with light of certain wavelengths. Lutein and zeaxanthin are found in the typical diet in foods such as egg yolks, corn, fruit, and vegetables. ${ }^{6}$ Meso-zeaxanthin, however, can be acquired through dietary
Correspondence: Lene Martin School of Health, Care and Social Welfare, Mälardalen University, Mälardalens högskola, PO Box 325, SE-63I 05 Eskilstuna, Sweden

$\mathrm{Tel}+46 \quad$ I6 I5 3202

Email Lene.Martin@mdh.se 
sources and is also formed within the macula via lutein conversion. ${ }^{7}$ The macular pigment enhances image quality by absorbing short wavelength light and also protects the retinal nerve cells from phototoxic damage by free radicals. ${ }^{8}$

Results from the long-running age-related eye disease studies (AREDS) indicate that carotenoid and antioxidant supplements significantly reduce the risk of visual loss in patients with AMD. ${ }^{9}$ Such treatment in the form of dietary supplements can be recommended for patients with intermediate and late AMD. ${ }^{10,11}$ However, the preventive effect of dietary supplementation was minor for those with early stage AMD, ${ }^{12}$ and no evidence has been presented to support routine nutritional supplementation for primary prevention. ${ }^{13}$ Results from genomics studies of AMD patients have suggested that gene-directed therapies could improve patient outcomes. ${ }^{14}$ However, this view has been disputed. ${ }^{9}$ Recently, Kijlstra and Berendschot ${ }^{15}$ suggested that AMD is a disease caused by hyperactive complement and thus should be classified as complementopathy and that nutrition may play a role in controlling the level of complement factor $\mathrm{D}$ in the circulation.

Addressing modifiable risk factors, such as smoking and nutrition, may improve AMD prevention. ${ }^{15}$ The association between smoking and AMD has been known for many years, ${ }^{16,17}$ and even though there is convincing evidence that smoking is harmful, $\sim 20 \%$ of the adult population continues to use cigarettes. ${ }^{18}$ Awareness regarding the effects of smoking on vision is low, ${ }^{19}$ although cigarette smoking generates oxidative stress, decreases antioxidant protection, and results in the generation of reactive oxygen and nitrogen species. Oxidative stress enhances disease onset in both the atrophic and neovascular forms of AMD, ${ }^{20}$ and a threefold increased risk of any type of AMD associated with current active smoking has been reported. ${ }^{21}$ Furthermore, smokers have a reduced intake of dietary antioxidants. ${ }^{22}$ Hence, smoking cessation should be the first recommendation given to patients at risk of or with AMD to prevent progression to late AMD. ${ }^{23}$ Consumption of fruits and vegetables containing the two carotenoid pigments lutein and zeaxanthin ${ }^{6}$ may be linked to a reduced risk of AMD. ${ }^{24}$

Several studies have recently been performed in order to determine how these scientific findings have influenced eye care professionals to recommend nutritional supplements, changes in diet, or smoking cessation. In a European study of ophthalmologists from seven countries, ${ }^{25}$ the proportion of patients receiving nutritional supplements ranged from 53\% to $78 \%$. The rate of recommendation of nutritional supplement was lowest in the UK and highest in Germany. The surveyed ophthalmologists were generally of the opinion that nutritional supplements were beneficial, at least during the early/intermediate-stage of AMD. ${ }^{25}$ Hence, dietary supplement recommendations seem to be routine when managing AMD, at least among ophthalmologists in Belgium, France, Germany, Italy, Portugal, Spain, and the UK, and the awareness of the recent clinical studies in the field is high. ${ }^{25}$

However, ophthalmologists are not the only eye care professionals who meet patients at risk of or with AMD. In recent decades, optometrists in many countries have taken an increasing part of the care of patients at risk of or with age-related eye diseases. A study from Australia showed that less than two-thirds of optometrists routinely discussed diets with their patients and just over $50 \%$ inquired about patients' use of nutritional supplements. ${ }^{26}$ Lawrenson and Evans conducted a survey among optometrists and ophthalmologists in the UK and found that these eye care professionals were actively engaged in providing nutritional advice to their older patients with family histories of AMD and patients with advanced AMD. ${ }^{27}$

The aim of the current study was to investigate the extent to which ophthalmologists and optometrists in Sweden recommend the use of nutritional supplements, changes in diet, or smoking cessation to patients at risk of or with signs of AMD. This study also determined how practitioners rate the strength of evidence for nutritional supplements in AMD management and which sources of information they consult to create recommendations for nutritional supplements in the prevention or treatment of AMD.

\section{Materials and methods}

A cross-sectional survey was performed, delivered entirely online, and hosted by Netigate ${ }^{\circledR}$ (http://www.netigate.se). The survey was developed for a similar study in the UK, ${ }^{27}$ translated into Swedish (the survey was also back translated to verify the accuracy of the translation), and piloted in a small group of optometrists and one ophthalmologist. An invitation to the ophthalmologists to take part in the survey was distributed as an advertisement in an electronic newsletter from the Swedish Ophthalmological Society, which is periodically sent to all members $(\mathrm{N} \approx 900)$. All Swedish optometrists $(\mathrm{N} \approx 800)$ included in the membership databases of their professional organization were invited by email or via an advertisement in an electronic newsletter to participate in the online survey. Both invitations included a hyperlink to the same survey home page. No exclusion criteria were used, meaning that all ophthalmologists and optometrists in Sweden were invited, regardless of their sub-specialties. 
Reminders to complete the survey were sent out twice via the respective organizations.

The survey contained 18 forced choice questions and one free text question and was organized into the following four sections: use of nutritional supplements, dietary advice, smoking and eye diseases, and strength of evidence and the sources of information regarding nutritional supplement interventions. The respondents were presented with three patient scenarios of different age, heredity, and symptoms of AMD: 1) scenario A: 55-year-old patient with no signs of AMD but with one or more parents and/or siblings affected by AMD (i.e., a patient at risk for AMD), 2) scenario B: 65-year-old patient with advanced AMD in one eye and early AMD in the other, and 3) scenario C: 75-year-old patient with advanced AMD in both eyes. They were asked whether they would advise nutritional supplements for each specified patient, and if so to indicate which supplement they would recommend from a list of those commercially available in Sweden. The respondents were also questioned as to whether they would ask patients about their smoking habits and if they would recommend smoking cessation. The scenarios were chosen to reflect the available information about the value of nutritional supplementation in AMD and were adopted from a previous study by Lawrenson and Evans with their permission. ${ }^{27}$ The suggested supplement choices representing those available in Sweden included the following: 1) vitamins $\mathrm{C}$ and $\mathrm{E}$ and lutein, zeaxanthin, copper, and zinc (corresponding to the AREDS2 formula), 2) lutein, meso-zeaxanthin, and zeaxanthin, 3) vitamins $\mathrm{A}, \mathrm{B}_{2}, \mathrm{C}$, and $\mathrm{E}$, and lutein, zeaxanthin, zinc, selenium, and copper, and 4) vitamins $\mathrm{C}$ and $\mathrm{E}$ and zinc, lutein, zeaxanthin, and omega-3 fatty acids. In the last part of the questionnaire, the respondents were asked to rate the strength of evidence to support the use of nutritional supplements in the prevention or treatment of AMD and which sources of information they consult to determine recommendations for nutritional supplements in AMD patients. The terminology adopted by the Grading of Recommendations Assessment, Development and Evaluation (GRADE) working group ${ }^{28}$ for quality of evidence (high, moderate, low, or very low) was used. For a more detailed description of the questions, see Lawrenson and Evans. ${ }^{27} \mathrm{An}$ incentive in the form of a prize draw for $£ 100$ in shopping vouchers was offered to those who completed the survey and voluntarily provided an email address. An informational email was sent to the participants, which contained an embedded link to the survey; this email informed them of the voluntary nature of their responses and that they could decline participation simply by not answering the survey. The email also stated that by answering the questionnaire, participants gave their informed consent. The respondents were also informed that their individual answers would be treated with confidentiality and would not be traceable to them or their health care unit.

The research was carried out in accordance with the Declaration of Helsinki (http://www.wma.net/ en/30publications/10policies/b3/index.html). According to the Swedish Law (2003: 460) for ethical review of research involving humans, no ethical approval was needed for this type of survey.

\section{Statistical analysis}

The answers were presented as percentages of valid responses. Statistical analysis of differences between the ophthalmologists and the optometrists was performed using Fisher's exact test and chi-square test.

\section{Results}

A total of 393 (full or partial) responses were received. Of these, $323(87 \%)$ were from optometrists and $48(13 \%)$ from ophthalmologists, which resulted in a response rate of $\approx 23 \%$. The response rate of optometrists was $40.3 \%$ and ophthalmologists was $5 \%$.

\section{Recommendations for nutritional supplements}

The Swedish optometrists were more likely to recommend micronutrient supplements for all scenarios than were the ophthalmologists. The largest difference regarding supplement recommendations was found in patients with no signs of AMD but with risk factors for the disease (see Table 1). A total of $75 \%$ of the respondents reported that they would recommend nutritional supplements to a patient with advanced AMD in one eye and early AMD in the other. The optometrists were more likely to recommend supplements containing macular carotenoids only (54\%), whereas the ophthalmologists recommended supplements also containing vitamins and minerals according to the AREDS2 formula (67\%).

\section{Dietary advice to patients at risk of or with advanced AMD}

The Swedish ophthalmologists were significantly more reluctant to provide dietary advice to patients with AMD than were the optometrists (Table 2). The most common advice given by both professionals was to increase consumption of green vegetables and oily fish to at least two times a week. Two-thirds of the ophthalmologists compared with one-third of the optometrists would never provide dietary advice to patients who only had risk factors for AMD. 
Table I Recommendations on nutritional supplements

\begin{tabular}{llll}
\hline $\begin{array}{l}\text { Patient } \\
\text { scenarios }\end{array}$ & $\begin{array}{l}\text { Optometrists/ } \\
\text { total responses (\%) } \\
\text { recommending } \\
\text { supplements }\end{array}$ & $\begin{array}{l}\text { Ophthalmologists/ } \\
\text { total responses (\%) } \\
\text { recommending } \\
\text { supplements }\end{array}$ & p-Value \\
\hline $\mathrm{A}$ & $162 / 323(50 . \mathrm{I})$ & $3 / 47(6)$ & $<0.0001$ \\
$\mathrm{~B}$ & $237 / 393(73.3)$ & $16 / 47(34)$ & 0.0009 \\
$\mathrm{C}$ & $\mathrm{III} / 323(34.3)$ & $4 / 47(8.5)$ & 0.0002 \\
\hline
\end{tabular}

Notes: A, 55-year-old patients with no signs of AMD but with one or more parents and/or siblings affected by AMD; B, 65-year-old patients with advanced AMD in one eye and early AMD in the other; C, 75-year-old patients with advanced AMD in both eyes.

Abbreviation: AMD, age-related macular degeneration.

Table 2 Swedish optometrists' and ophthalmologists' recommendations on diet for patients who are at risk of developing AMD and those with established AMD

\begin{tabular}{llll}
\hline Dietary advice & $\begin{array}{l}\text { Optometrists/ } \\
\text { total responses } \\
\text { (\%) }\end{array}$ & $\begin{array}{l}\text { Ophthalmologists/ } \\
\text { total responses } \\
\text { (\%) }\end{array}$ & $p$-Value \\
\hline $\begin{array}{l}\text { Patients at risk } \\
\quad \text { Always or very } \\
\text { often }\end{array}$ & $69 / 272(25)$ & $4 / 43(9)$ & $<0.05$ \\
$\begin{array}{l}\text { Sometimes } \\
\quad \text { Never }\end{array}$ & $113 / 272(42)$ & $11 / 43(26)$ & \\
$\begin{array}{l}\text { Established AMD } \\
\text { Always or very } \\
\text { often }\end{array}$ & $76 / 272(33)$ & $28 / 43(65)$ & $<0.01$ \\
$\begin{array}{l}\text { Sometimes } \\
\text { Never }\end{array}$ & $120 / 276(43)$ & $5 / 44(12)$ & $<0.05$ \\
\hline
\end{tabular}

Abbreviation: AMD, age-related macular degeneration.

\section{Recommendations on smoking}

Swedish ophthalmologists were significantly more likely to take a smoking history from their new patients than were the optometrists and to inform patients about the relationship between smoking and eye disease. The ophthalmologists were also significantly more likely to recommend that all of their patients quit smoking than were the optometrists (Table 3).

\section{Rating the evidence for nutritional supplement recommendations in AMD and sources of information}

The optometrists rated the strength of the evidence significantly higher than did the ophthalmologists (Table 4) regarding both the prevention and slowing of AMD progression.

Both the optometrists and ophthalmologists relied on conference presentations, expert opinions, and articles in peer-reviewed journals as the basis for their recommendations regarding nutritional supplements. Conference presentations were most common (68\% and 65\%, respectively), and Cochrane reviews or bibliographic databases (Medline, PubMed) were used to a lesser extent by both groups of
Table 3 Smoking history acquisition and information and recommendations provided regarding smoking cessation

\begin{tabular}{|c|c|c|c|}
\hline Smoking advice & $\begin{array}{l}\text { Optometrists/ } \\
\text { total responses } \\
\text { (\%) }\end{array}$ & $\begin{array}{l}\text { Ophthalmologists/ } \\
\text { total responses (\%) }\end{array}$ & $p$-Value \\
\hline History taking & & & $<0.0001$ \\
\hline $\begin{array}{l}\text { Always or very } \\
\text { often }\end{array}$ & 46/27I (17) & $19 / 43(44)$ & \\
\hline Sometimes & 75/27I (28) & 19/43 (44) & \\
\hline Never & $|50 / 27|(55)$ & $5 / 43(12)$ & \\
\hline Information given & & & $<0.0001$ \\
\hline $\begin{array}{l}\text { Always or very } \\
\text { often }\end{array}$ & $84 / 269(31)$ & $23 / 42(53)$ & \\
\hline Sometimes & $83 / 269(31)$ & $19 / 42(44)$ & \\
\hline Never & $102 / 269(38)$ & $1 / 42(2)$ & \\
\hline $\begin{array}{l}\text { Recommend } \\
\text { cessation }\end{array}$ & & & $<0.0001$ \\
\hline $\begin{array}{l}\text { Always or very } \\
\text { often }\end{array}$ & $5 \mathrm{I} / 268(19)$ & $27 / 44(63)$ & \\
\hline Sometimes & $53 / 268(20)$ & I6/44 (37) & \\
\hline Never & $164 / 268(61)$ & $0 / 44(0)$ & \\
\hline
\end{tabular}

professionals. A total of $10 \%$ of the optometrists and $6 \%$ of the ophthalmologists did not use any of these sources. Other sources of information reported were information from manufacturers, university education and courses, Internetrelated sources, and reports from patients.

\section{Discussion}

The increasing life span in Europe has led a large number of patients to develop risks for age-related eye diseases, such as AMD. Targeting modifiable risk factors (e.g., smoking, diet, and nutrition) might represent a simple and cost-effective strategy to reduce the burden of disease ${ }^{29}$ as micronutrients have been shown to beneficially influence the course of AMD. ${ }^{9}$ In the current study, significant differences were observed between the reported practices of the participating optometrists and ophthalmologists regarding the use of micronutrients, with optometrists being more likely to recommend nutritional supplements than the ophthalmologists. According to AREDS, a patient with no signs of AMD but with risk factors for the disease will not benefit from using nutritional supplements. ${ }^{9}$ Nevertheless, half of the optometrists in the current study reported that they would recommend nutritional supplements to these patients. A patient with advanced AMD in one eye and early AMD in the other, who should be recommended supplements according to the results from the AREDS, ${ }^{9,11}$ would receive supplement recommendations from $67 \%$ of the ophthalmologists and $54 \%$ of the optometrists in this study. 
Table 4 The strength of evidence for recommending nutritional supplement for prevention or to slow down the progression of AMD

\begin{tabular}{llllll}
\hline $\begin{array}{l}\text { Patient } \\
\text { scenarios }\end{array}$ & Prevention (opt) & $\begin{array}{l}\text { Prevention } \\
\text { (ophth) }\end{array}$ & p-Value & $\begin{array}{l}\text { Slowing down the } \\
\text { progression (opt) }\end{array}$ & $\begin{array}{l}\text { Slowing down the } \\
\text { progression (ophth) }\end{array}$ \\
\hline High strength & $40 / 267(15 \%)$ & $0 / 41(0 \%)$ & $<0.0001$ & $45 / 262(17 \%)$ & $2 / 40(5 \%)$ \\
Moderate strength & $158 / 267(59 \%)$ & $4 / 41(10 \%)$ & & $158 / 262(60 \%)$ & $5 / 40(13 \%)$ \\
Low strength & $59 / 267(22 \%)$ & $27 / 41(66 \%)$ & & $54 / 262(21 \%)$ & $24 / 40(60 \%)$ \\
Very low strength & $10 / 267(4 \%)$ & $10 / 41(24 \%)$ & & $5 / 262(2 \%)$ & $9 / 40(23 \%)$ \\
\hline
\end{tabular}

Abbreviations: Opt, optometrists; ophth, ophthalmologists; AMD, age-related macular degeneration.

The Swedish respondents did not take smoking histories in new patients, provided advice regarding smoking, or recommended smoking cessation to the same extent as did the UK respondents, ${ }^{27}$ despite the fact that the proportions of smokers in the two countries are similar (UK 19.9\% and Sweden 20.4\%). ${ }^{18}$ Compared with the ophthalmologists, the Swedish optometrists were significantly less likely to ask their new patients about smoking and to inform them about the relationship between smoking and eye diseases and recommend smoking cessation. This might be explained by a perception that advice about smoking cessation is a form of medical care and primarily the responsibility of the general medical practitioner. ${ }^{26}$

At $16.7 \%$, the prevalence of smoking is somewhat lower in Australia than in Sweden and the UK, ${ }^{18}$ yet almost half of Australian optometrists routinely ask their patients about their smoking habits. ${ }^{26}$ In Canada, optometrists do not routinely engage in tobacco use prevention and cessation practices, despite awareness of the impact of smoking on ocular health. ${ }^{30}$ A recent study from the UK showed that targeted educational intervention can change practice. ${ }^{31}$ Kennedy and Douglas $^{32}$ stated that optometrists can have an important role in tobacco use prevention and cessation and presented several techniques and strategies that could be implemented in optometric practice. It has been reported that a majority of eye care providers desire additional training and resources to support smoking cessation. ${ }^{30,33}$

Swedish optometrists were also more reluctant in giving dietary advice than were UK optometrists, but when they did, more Swedish respondents recommended the intake of oily/fatty fish than did UK professionals..$^{27}$ The so-called Nordic diet includes intake of fatty fish, which has been shown to increase the levels of n-3 polyunsaturated fatty acids in serum. ${ }^{34}$ However, the previous reported positive effect of dietary patterns ${ }^{35,36}$ and consumption of oily fish ${ }^{37,38}$ in observational studies of AMD outcomes has not yet been supported by randomized controlled studies..$^{39}$ In Australia, the most common reason for recommendations on consuming fish oil was dry eye disease and not AMD. ${ }^{26}$
In Sweden, as in the UK, the micronutrient supplements marketed for the prevention or treatment of AMD are overthe-counter products and can be purchased from a variety of retail outlets. A recent study ${ }^{40}$ found that the majority of the available ocular micronutrient supplements in the US did not contain identical ingredients and dosages to the formula used in the AREDS or AREDS2 trials, and many had manufacturer claims that could not be supported by research evidence. This emphasizes the importance for eye care professionals to use evidence-based knowledge to educate their patients and recommend appropriate products. The data from Swedish ophthalmologists and optometrists in the current study indicate that ophthalmologists tend to be somewhat restrictive when recommending supplements, whereas on the other hand optometrists seem to be overly enthusiastic for treatment and frequently recommend products not supported by evidence. Although not specifically investigated in the current survey, it cannot be excluded that some optometrists may have an economic incentive for recommending supplements.

Integrating the best current research evidence into clinical decision making represents a significant challenge for eye care professionals. The amount of new research on AMD is overwhelming, and $>3500$ articles in ophthalmology have been published within the past 2 years (http://www.ncbi.nlm. nih.gov/pubmed). The dissemination of new research results is inadequate, and conventional educational activities focusing on passive knowledge acquisition have little impact on the behavior of health care professionals. ${ }^{41}$ Sometimes the barriers are patient-related, suggesting that current guidelines do not always adequately incorporate patient preferences, needs, and abilities. ${ }^{42}$

As early as 1998, it was proposed that an implementation strategy is needed in order to change practices and to decrease the delay between the generation of evidence and its application. ${ }^{41}$ The current study found that the majority of survey respondents relied on conference presentations and articles in peer-reviewed journals to support their decision making on the use of supplements, with relatively few accessing bibliographic databases or Cochrane reviews. These results were similar to the findings in the UK. ${ }^{27}$ 
In the current study, the optometrists and ophthalmologists were asked to rate the strength of evidence to support the use of nutritional supplements in the prevention or treatment of AMD. Both the Swedish and UK optometrists ${ }^{27}$ rated the evidence as rather high; however, it is unclear how they interpreted the term "evidence", as they reported relying on conference presentations and expert opinion as the basis for their recommendations rather than published reports. Even if such sources do contribute to clinical practice, they should not be called evidence. ${ }^{43}$

\section{Limitations and strengths of the study}

The total response rate in the current study $(\sim 23 \%)$ was rather low, especially for the ophthalmologists, but higher than that reported in previous studies, ${ }^{25-27}$ in which the response rates ranged from $5 \%$ to $16 \%$. The majority of responders were optometrists $(87 \%)$ and, therefore, the results reflect optometric practice rather than the overall management of AMD patients in eye care. It cannot be excluded that the ophthalmologists taking part in the survey had a special interest in AMD and nutritional supplements, which would lead to overestimation of the proportion of Swedish ophthalmologists recommending micronutrients. Still, the results may be interesting since the increase in the aging population along with a shortage of ophthalmologists may lead to an increased dependence on optometrists in the care of AMD patients in Sweden as in the UK.

\section{Conclusion}

Optometrists were more likely than ophthalmologists to recommend nutritional supplements for AMD and provided significantly more advice about diet, both regarding patients at risk and patients with established AMD. On the other hand, the ophthalmologists, albeit few in the current study, were more prone to rely on the findings of AREDS regarding AMD when recommending nutritional supplements and smoking cessation. Targeted education and implementation strategies may be required to establish common evidence-based strategies for AMD management that can be adhered to by all eye care professionals involved.

\section{Acknowledgments}

The author is grateful to the Swedish Ophthalmological Society and to Maria Nilsson, PhD, and Rune Brautaset, $\mathrm{PhD}$, School of Optometry, Karolinska Institutet, Stockholm, Sweden, for their help with the distribution of the link to the survey and to all the respondents who took the time to complete the survey. The author would also like to thank Professor John Lawrenson, PhD, City, University of London, London, UK, for permission to translate and use the questionnaire. The author thanks the American Journal Experts (AJE) for performing language editing (https://www.aje.com/).

\section{Disclosure}

The author reports no conflict of interest in this work.

\section{References}

1. Bressler NM. Age-related macular degeneration is the leading cause of blindness. JAMA. 2004;291(15):1900-1901.

2. Friedman DS, O' Colmain BJ, Muñoz B, et al; Eye Diseases Prevalence Research Group. Prevalence of age-related macular degeneration in the United States. Arch Ophthalmol. 2004;122(4):564-572.

3. Green WR. Histopathology of age-related macular degeneration. $\mathrm{Mol}$ Vis. 1999;5:27.

4. Barnett BP, Handa JT. Retinal microenvironment imbalance in dry age-related macular degeneration: a mini-review. Gerontology. 2013;59(4):297-306.

5. Mao H, Seo SJ, Biswal MR, et al. Mitochondrial oxidative stress in the retinal pigment epithelium leads to localized retinal degeneration. Invest Ophthalmol Vis Sci. 2014;55(7):4613-4627.

6. Sommerburg O, Keunen JE, Bird AC, van Kuijk FJ. Fruits and vegetables that are sources for lutein and zeaxanthin: the macular pigment in human eyes. Br J Ophthalmol. 1998;82(8):907-910.

7. Gerster H. Review: antioxidant protection of the ageing macula. Age Ageing. 1991;20(1):60-69.

8. Rasmussen HM, Muzhingi T, Eggert EM, Johnson EJ. Lutein, zeaxanthin, meso-zeaxanthin content in egg yolk and their absence in fish and seafood. J Food Compost Anal. 2012;27(2):139-144.

9. Chew EY, Clemons TE, Agrón E, et al; Age-Related Eye Disease Study Research Group. Long-term effects of vitamins $\mathrm{C}$ and $\mathrm{E}, \beta$-carotene, and zinc on age-related macular degeneration: AREDS report no. 35. Ophthalmology. 2013;120(8):1604-1611.

10. National Eye Institute. Facts about age-related macular degeneration (AMD). Available from: https://www.nei.nih.gov/health/maculardegen/. Accessed November 20, 2016.

11. Algvere PV, Kvanta A, Seregard S. Drusen maculopathy: a risk factor for visual deterioration. Acta Ophthalmol. 2016;94(5):427-433.

12. Kansagara D, Gleitsmann K, Gillingham M, Freeman M, Quiñones A. Nutritional Supplements for Age-Related Macular Degeneration: A Systematic Review. VA-ESP Project \#05-225. Washington, DC: Department of Veterans Affairs (US); 2012. Available from: http://www.ncbi. nlm.nih.gov/books/NBK84269/. Accessed November 20, 2016.

13. Evans JR, Lawrenson JG. A review of the evidence for dietary interventions in preventing or slowing the progression of age-related macular degeneration. Ophthalmic Physiol Opt. 2014;34(4):390-396.

14. Awh CC, Lane AM, Hawken S, Zanke B, Kim IK. CFH and ARMS2 genetic polymorphisms predict response to antioxidants and zinc in patients with age-related macular degeneration. Ophthalmology. 2013;120(11):2317-2323.

15. Kijlstra A, Berendschot TT. Age-related macular degeneration: a complementopathy? Ophthalmic Res. 2015;54(2):64-73.

16. Paetkau ME, Boyd TA, Grace M, Bach-Mills J, Winship B. Senile disciform macular degeneration and smoking. Can J Ophthalmol. 1978;13(2):67-71.

17. Cong R, Zhou B, Sun Q, Gu H, Tang N, Wang B. Smoking and the risk of age-related macular degeneration: a meta-analysis. Ann Epidemiol. 2008;18(8):647-656.

18. World Health Organization. Prevalence of tobacco smoking. Available from: http://www.who.int/gho/tobacco/use/en. Accessed November 20, 2016. 
19. Galor A, Lee DJ. Effects of smoking on ocular health. Curr Opin Ophthalmol. 2011;22(6):477-482.

20. Lois N, Abdelkader E, Reglitz K, Garden C, Ayres JG. Environmental tobacco smoke exposure and eye disease. Br J Ophthalmol. 2008; 92(10):1304-1310.

21. Smith W, Assink J, Klein R, et al. Risk factors for age-related macular degeneration: pooled findings from three continents. Ophthalmology. 2001;108(4):697-704.

22. Marangon K, Herbeth B, Lecomte E, et al. Diet, antioxidant status, and smoking habits in French men. Am J Clin Nutr. 1998;67(2):231-239.

23. Downie LE, Keller PR. Nutrition and age-related macular degeneration: research evidence in practice. Optom Vis Sci. 2014;91(8):821-831.

24. Ersoy L, Ristau T, Lechanteur YT, et al. Nutritional risk factors for age-related macular degeneration. Biomed Res Int. 2014;2014:413150.

25. Aslam T, Delcourt C, Holz F, et al. European survey on the opinion and use of micronutrition in age-related macular degeneration: 10 years on from the Age-Related Eye Disease Study. Clin Ophthalmol. 2014;8: 2045-2053.

26. Downie LE, Keller PR. The self-reported clinical practice behaviors of Australian optometrists as related to smoking, diet and nutritional supplementation. PLoS One. 2015;10(4):e0124533.

27. Lawrenson JG, Evans JR. Advice about diet and smoking for people with or at risk of age-related macular degeneration: a cross-sectional survey of eye care professionals in the UK. BMC Public Health. 2013;13:564

28. Atkins D, Best D, Briss PA, et al; GRADE Working Group. Grading quality of evidence and strength of recommendations. $B M J$. 2004;328(7454):1490.

29. Kumar S, Preetha G. Health promotion: an effective tool for global health. Indian J Community Med. 2012;37(1):5-12.

30. Kennedy RD, Spafford MM, Douglas O, et al. Patient tobacco use in optometric practice: a Canada-wide study. Optom Vis Sci. 2014;91(7): 769-777.

31. Lawrenson JG, Roberts CA, Offord L. A pilot study of the feasibility of delivering a brief smoking cessation intervention in community optometric practice. Public Health. 2015;129(2):149-151.
32. Kennedy RD, Douglas O. Strategies to help patients to stop smoking: the optometrist's perspective. Clin Opt. 2015;7:103-113.

33. Caban-Martinez AJ, Davila EP, Lam BL, et al. Age-related macular degeneration and smoking cessation advice by eye care providers: a pilot study. Prev Chronic Dis. 2011;8(6):A147.

34. Adamsson V, Cederholm T, Vessby B, Risérus U. Influence of a healthy Nordic diet on serum fatty acid composition and associations with blood lipoproteins - results from the NORDIET study. Food Nutr Res. 2014;58:24114.

35. Mares JA, Voland RP, Sondel SA, et al. Healthy lifestyles related to subsequent prevalence of age-related macular degeneration. Arch Ophthalmol. 2011;129(4):470-480.

36. Amirul Islam FM, Chong EW, Hodge AM, et al. Dietary patterns and their associations with age-related macular degeneration: the Melbourne collaborative cohort study. Ophthalmology. 2014;121(7): 1428-1434.e2.

37. Christen WG, Schaumberg DA, Glynn RJ, Buring JE. Dietary $\omega-3$ fatty acid and fish intake and incident age related macular degeneration in women. Arch Ophthalmol. 2011;129(7):921-929.

38. Chong EW, Robman LD, Simpson JA, et al. Fat consumption and its association with age-related macular degeneration. Arch Ophthalmol. 2009;127(5):674-680

39. Evans JR, Lawrenson JG. Antioxidant vitamin and mineral supplements for slowing the progression of age-related macular degeneration. Cochrane Database Syst Rev. 2012;11:CD000254.

40. Yong JJ, Scott IU, Greenberg PB. Ocular nutritional supplements: are their ingredients and manufacturers' claims evidence-based? Ophthalmology. 2015;122(3):595-599.

41. Haines A, Donald A. Making better use of research findings. $B M J$ 1998;317(7150):72-75.

42. Lugtenberg M, Burgers JS, Besters CF, Han D, Westert GP. Perceived barriers to guideline adherence: a survey among general practitioners BMC Fam Pract. 2011;12:98.

43. Keller PR. The evidence in evidence-based practice. Why the confusion? Clin Exp Optom. 2012;95(6):618-620.

\section{Clinical Optometry}

\section{Publish your work in this journal}

Clinical Optometry is an international, peer-reviewed, open access journa publishing original research, basic science, clinical and epidemiological studies, reviews and evaluations on clinical optometry. All aspects of patient care are addressed within the journal as well as the practice of optometry including economic and business analyses. Basic and clinical

\section{Dovepress}

research papers are published that cover all aspects of optics, refraction and its application to the theory and practice of optometry. The manuscript management system is completely online and includes a very quick and fair peer-review system, which is all easy to use. Visit http://www.dovepress. com/testimonials.php to read real quotes from published authors. 